\title{
Modelos para a estimação da área foliar de feijão de porco por dimensões foliares
}

\author{
Marcos Toebe ( $\left.{ }^{1}\right)$; Alberto Cargnelutti Filho $\left({ }^{2 *}\right)$; Cláudia Burin $\left({ }^{2}\right)$; André Luis Fick $\left({ }^{2}\right)$; Ismael Mario \\ Márcio Neu ( $\left.{ }^{2}\right)$; Gabriele Casarotto ('); Bruna Mendonça Alves (') \\ (') Universidade Federal de Santa Maria (UFSM), Programa de Pós-Graduação em Agronomia, 97105-900 Santa Maria (RS), Brasil. \\ (2) Universidade Federal de Santa Maria, Centro de Ciências Rurais (UFSM/CCR), 97105-900 Santa Maria (RS), Brasil. \\ (*) Autor correspondente: cargnelutti@pq.cnpq.br
}

Recebido: 4/maio/2011; Aceito: 29/set./2011

\begin{abstract}
Resumo
O objetivo deste trabalho foi modelar a área foliar de feijão de porco determinada por fotos digitais em função do comprimento ou da largura e/ou do produto comprimento vezes largura do limbo do folíolo central da folha. Em seis períodos de desenvolvimento da cultura (29, 43, 57, 73, 87 e 101 dias após a emergência) foram coletadas, aleatoriamente, 745 folhas. Cada folha é composta pelos folíolos esquerdo, central e direito. Nas 745 folhas foi mensurado o comprimento (CFC) e a largura (LFC) e calculado o produto do comprimento pela largura (CFC $\times$ LFC) do limbo do folíolo central. A seguir, determinou-se a área foliar (soma da área dos folíolos esquerdo, central e direito) por meio do método de fotos digitais (Y). Do total de folhas, foram separadas, aleatoriamente, 605 folhas para a construção de modelos do tipo quadrático, potência e linear de $Y$ em função do CFC, da LFC, e/ou do CFC x LFC e 140 folhas para a validação dos modelos. Em feijão de porco, o modelo tipo potência $\left(\hat{Y}=3,7046 x^{1,8747}, R^{2}=0,9757\right)$ da largura do limbo do folíolo central é adequado para estimar a área foliar obtida por fotos digitais.
\end{abstract}

Palavras-chave: Canavalia ensiformis, fotos digitais, método não-destrutivo.

\section{Leaf area prediction models for jack bean by leaf dimensions}

\section{Abstract}

The objective of this work was to model the leaf area of jack bean determined by digital photos with the length or width and/or the product length $\times$ width of the central leaflet limb of the leaf. At six periods of crop development $(29,43,57,73,87$ and 101 days after emergence) 745 leaves were randomly collected. Each leaf is composed by left, center and right leaflets. The length (CFC) and width (LFC) were measured and the product length by the width (CFC $\times$ LFC) of the central leaflet calculated. The leaf area (sum of the leaf area of the left, center and right leaflets) was calculated by the method of digital photos (Y). An amount of 605 leaves were used to build models of the type quadratic, potency and linear, considering $Y$ as function of the CFC, LFC and/or CFC $\times$ LFC. For validation, 140 leaves were used. The potency model of the leaf area obtained by method of digital photos $\left(\hat{Y}=3.7046 x^{1.8747}, R^{2}=0.9757\right)$ based on the width central leaflet, is adequate to estimate the leaf area in jack bean.

Key words: Canavalia ensiformis, digital photos, non-destructive method.

O feijão de porco (Canavalia ensiformis) é uma espécie leguminosa utilizada em sistemas de conservação de solos, devido à sua elevada capacidade de fixação biológica de nitrogênio e adaptação a solos de baixa fertilidade. Segundo TeIxeIra et al. (2010), quando se realiza o consórcio de milheto com feijão de porco, ocorre aumento da quantidade de matéria seca produzida e da velocidade de decomposição da palhada, com maior liberação de nitrogênio, cálcio e magnésio, em relação ao milheto solteiro. $\mathrm{O}$ feijão de porco também possui potencial fitoextrator de metais pesados em solos contaminados (Almeida et al., 2008) e efeito alelopático sobre as plantas daninhas (Souza FilHo, 2002).
A determinação da área foliar é importante indicador na avaliação do crescimento vegetal. A área foliar pode ser determinada diretamente através do método de fotos digitais. De acordo com Tavares JúnIOR et al. (2002), em cafeeiro, o processamento de imagens digitais é considerado adequado e exato para a estimação da área foliar em substituição ao método LI-COR (método padrão). Segundo Adami et al. (2008), o método de fotos digitais pode substituir o método LI-COR, em folíolos íntegros e danificados de soja, com vantagens de custo inferior e acurácia similar, sem a dependência de um método de calibração. 
Indiretamente, a área foliar pode ser obtida através de modelos de estimação da área foliar em função das dimensōes lineares das folhas, conforme já desenvolvido em soja (Adami et al., 2008), em Sida cordifolia e Sida rhombifolia (BIANCO et al., 2008), em Curcumaalismatifolia e Curcuma zedoaria (Pinto et al., 2008) e em crambe (Toebe et al., 2010). Admitindo, que a forma da folha é uma característica morfológica específica, dependente da relaçáo entre comprimento e largura e da quantidade de recortes na borda do limbo foliar, existe a necessidade de se criar modelos para cada espécie (Pinto et al., 2008). Assim, o objetivo deste trabalho foi modelar a área foliar de feijão de porco (Canavalia ensiformis) determinada por fotos digitais em função do comprimento, ou da largura e/ou do produto comprimento vezes largura do limbo do folíolo central da folha.

Foi desenvolvido um experimento de $256 \mathrm{~m}^{2}$ com a cultura de feijấo de porco. O espaçamento foi de $0,5 \mathrm{~m}$ entre fileiras e $0,125 \mathrm{~m}$ entre plantas na fileira, totalizando 16 plantas por $\mathrm{m}^{2}$. A semeadura foi realizada em 12/11/2010 com adubação de base de $40 \mathrm{~kg} \mathrm{ha}^{-1}$ de N, $150 \mathrm{~kg} \mathrm{ha}^{-1}$ de $\mathrm{P}_{2} \mathrm{O}_{5}$ e $100 \mathrm{~kg} \mathrm{ha}^{-1}$ de $\mathrm{K}_{2} \mathrm{O}$. Aos 29 e 43 dias após a emergência (DAE), foram coletadas, respectivamente, 90 e 95 folhas, e em cada um dos demais períodos $(57,73,87$ e
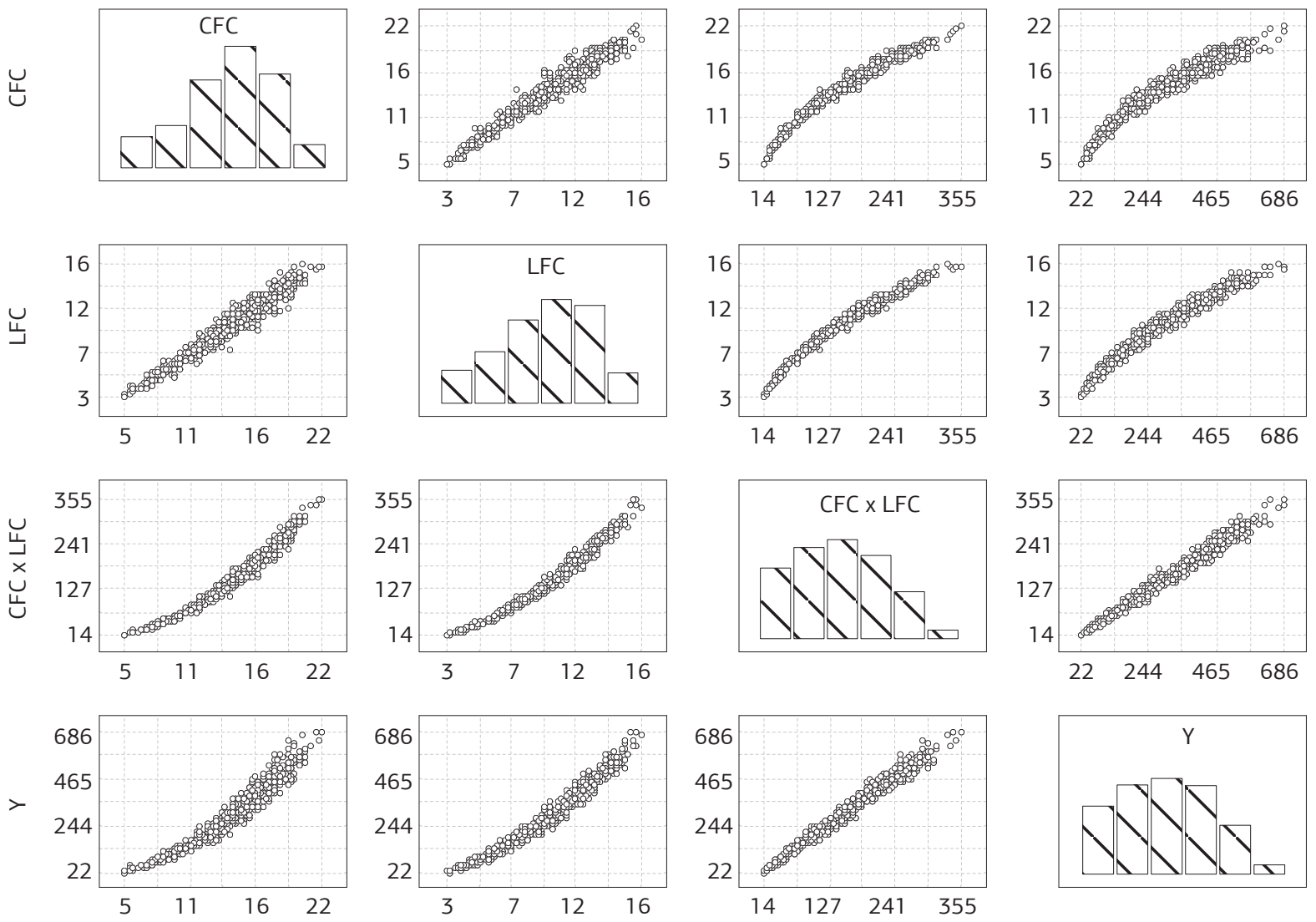

CFC

101 DAE), coletaram-se 140 folhas, de maneira aleatória, dentro da área experimental, totalizando 745 folhas, compostas de três folíolos (esquerdo, central e direito).

Nessas 745 folhas, foi mensurado o comprimento (CFC) e a largura (LFC) do limbo do folíolo central, com régua milimetrada. Em seguida, foi calculado o produto comprimento vezes largura ( $\mathrm{CFC} \times \mathrm{LFC})$ do limbo do folíolo central. Após, as mesmas folhas (compostas por três folíolos) foram fotografadas sob papel milimetrado por meio de uma câmera digital da marca Sony, modelo DSC-W110. Essas imagens (fotos) foram processadas com o programa Sigma Scan Pro v. 5.0 (Jandel Scientific, 1991), para a determinação da área foliar (soma da área foliar dos folíolos esquerdo, central e direito) por meio do método de fotos digitais $(\mathrm{Y})$.

Posteriormente, dentre as 745 folhas foram selecionadas, aleatoriamente, 140 folhas, utilizadas somente na validação dos modelos. Com os dados do CFC, da LFC, do CFC $\times$ LFC e de Y das 605 folhas restantes, foram feitos histogramas de frequência e gráficos de dispersão. Também, foram calculadas medidas de tendência central, de variabilidade, de assimetria e de curtose e verificada a normalidade, por meio do teste de Kolmogorov-Smirnov. Em seguida, com os dados dessas 605 folhas, modelou-se
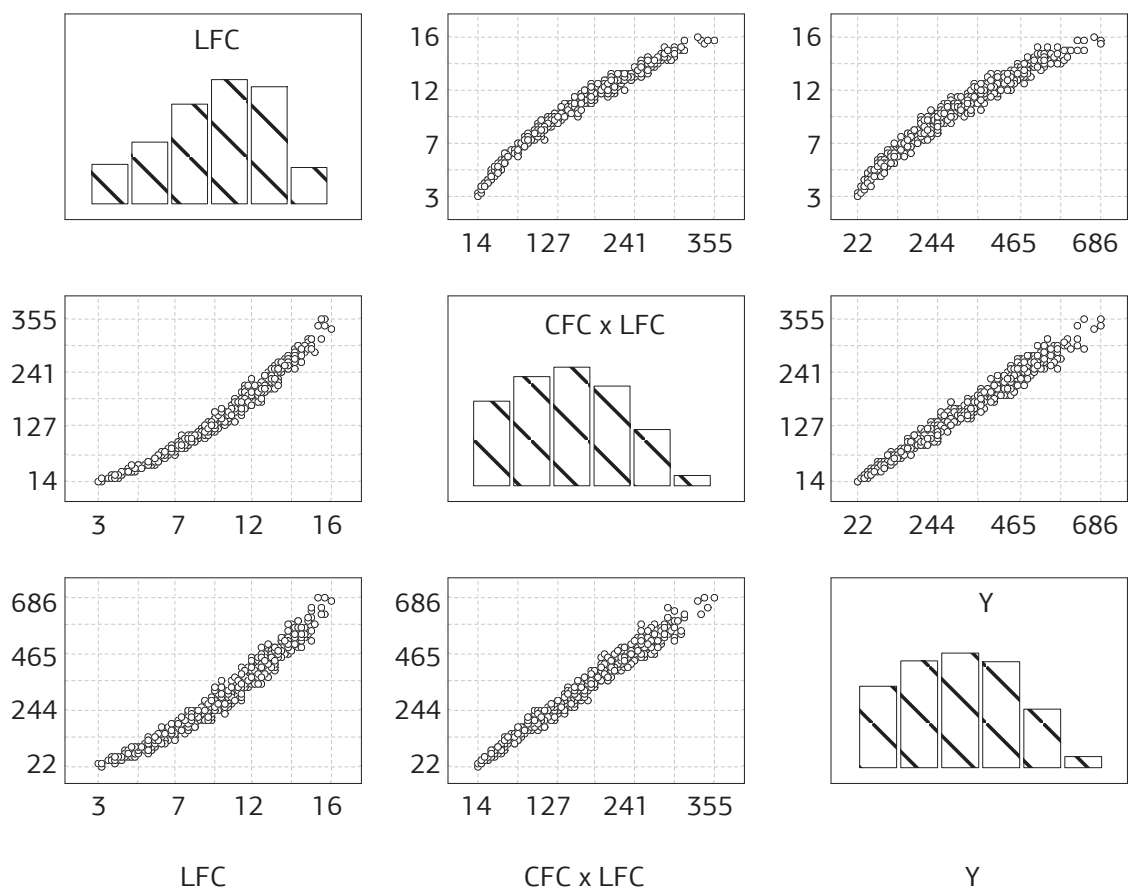

CFC x LFC

Y

Figura 1. Matriz com o histograma de frequência (na diagonal) e gráficos de dispersão entre o comprimento, em cm (CFC), a largura, em $\mathrm{cm}(\mathrm{LFC})$, o produto comprimento vezes largura $(\mathrm{CFC} \times \mathrm{LFC})$ do limbo do folíolo central e a área foliar determinada por fotos digitais, em $\mathrm{cm}^{2}(\mathrm{Y})$ de 605 folhas de feijão de porco (Canavalia ensiformis). 
a área foliar determinada por fotos digitais $(\mathrm{Y})$ em função do CFC, ou da LFC e/ou do CFC $\times$ LFC, por meio dos modelos: quadrático $\left(Y=a+b x+c x^{2}\right)$, potência $\left(Y=a x^{b}\right)$ e linear $(\mathrm{Y}=\mathrm{a}+\mathrm{bx})$, totalizando nove modelos (três modelos $x$ três variáveis independentes).

A validação dos modelos de estimação de área foliar foi realizada com base nos 140 valores estimados pelo modelo $\left(\hat{Y}_{i}\right)$ e os 140 valores observados $\left(\mathrm{Y}_{\mathrm{i}}\right)$. Em cada modelo, foi ajustada uma regressão linear simples $\left(\hat{\mathrm{Y}}_{\mathrm{i}}=\mathrm{a}+\mathrm{bY}\right)$ da área foliar estimada pelo modelo (variável dependente), em função da área foliar observada (variável independente). Foram testadas as hipóteses $\mathrm{H}_{0}: \mathrm{a}=0$ versus $\mathrm{H}_{1}: \mathrm{a} \neq 0$ e $\mathrm{H}_{0}: \mathrm{b}=1$ versus $\mathrm{H}_{1}$ : $\mathrm{b} \neq 1$, por meio do teste $\mathrm{t}$ de Student a 5\% de probabilidade. A seguir, foram calculados os coeficientes de correlação linear de Pearson $(r)$ e de determinação $\left(R^{2}\right)$ entre $\hat{Y}_{\mathrm{i}}$ e $Y_{i}$. Para cada modelo, foi calculado o erro absoluto médio (EAM), a raiz do quadrado médio do erro (RQME) e o índice d de Willmott (Willmotт, 1981), por meio, respectivamente, das expressóes:

$\mathrm{EAM}=\frac{\sum_{\mathrm{i}=1}^{\mathrm{n}}\left|\hat{\mathrm{Y}}_{\mathrm{i}}-\mathrm{Y}_{\mathrm{i}}\right|}{\mathrm{n}} \quad \mathrm{RQME}=\sqrt{\frac{\sum_{\mathrm{i}=1}^{\mathrm{n}}\left(\hat{\mathrm{Y}}_{\mathrm{i}}-\mathrm{Y}_{\mathrm{i}}\right)^{2}}{\mathrm{n}}}$

$d=1-\left[\frac{\sum_{i=1}^{n}\left(\hat{Y}_{i}-Y_{i}\right)^{2}}{\sum_{i=1}^{n}\left(\left|\hat{Y}_{i}-\bar{Y}\right|+\left|Y_{i}-\bar{Y}\right|\right)^{2}}\right]$,

e

em que $\hat{Y}_{i}$ são os valores estimados de área foliar, $\mathrm{Y}_{\mathrm{i}}$ os valores observados de área foliar por meio do método de

Tabela 1. Número de folhas (n), mínimo, máximo, média, coeficiente de variação (CV), variância, curtose, assimetria e p-valor do teste de kolmogorov-Smirnov do comprimento, em $\mathrm{cm}(\mathrm{CFC})$, da largura, em $\mathrm{cm}$ (LFC), do produto comprimento vezes largura (CFC $\times$ LFC) do limbo do folíolo central e da área foliar, em $\mathrm{cm}^{2}$ (soma da área foliar dos folíolos esquerdo, central e direito) determinada por fotos digitais (Y), de 605 folhas de feijão de porco (Canavalia ensiformis)

\begin{tabular}{|c|c|c|c|c|c|c|c|c|c|}
\hline Variável & n & Mínimo & Máximo & Média & CV(\%) & Variância & Curtose (1) & Assimetria ${ }^{(2)}$ & p-valor \\
\hline & & & & & & ênc & & & ------ \\
\hline CFC & 75 & 4,700 & 21,300 & 13,712 & 31,613 & 18,791 & $1,997^{\mathrm{ns}}$ & $-0,397^{n s}$ & 0,352 \\
\hline LFC & 75 & 3,200 & 15,900 & 9,536 & 33,320 & 10,096 & $2,028^{\text {ns }}$ & $-0,354^{\mathrm{ns}}$ & 0,394 \\
\hline$C F C \times L F C$ & 75 & 15,040 & 338,670 & 144,052 & 55,588 & $6.412,083$ & $2,058^{\text {ns }}$ & $0,060^{\text {ns }}$ & 0,344 \\
\hline Y & 75 & 22,203 & 622,358 & 271,169 & 57,499 & $24.311,091$ & $1,893^{*}$ & $0,024^{\text {ns }}$ & 0,292 \\
\hline \multicolumn{10}{|c|}{ 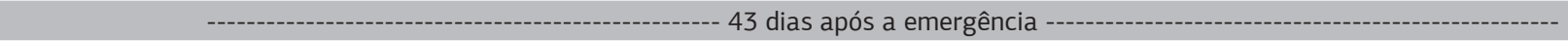 } \\
\hline CFC & 75 & 6,600 & 22,300 & 15,243 & 30,810 & 22,055 & $1,707^{*}$ & $-0,372^{\text {ns }}$ & 0,074 \\
\hline LFC & 75 & 4,400 & 15,900 & 10,727 & 32,028 & 11,803 & $1,698^{*}$ & $-0,344^{\text {ns }}$ & 0,049 \\
\hline $\mathrm{CFC} \times \mathrm{LFC}$ & 75 & 29,480 & 354,570 & 179,273 & 54,446 & $9.527,246$ & $1,586^{*}$ & $-0,073^{\text {ns }}$ & 0,166 \\
\hline Y & 75 & 52,274 & 686,299 & 336,926 & 56,675 & $36.462,485$ & $1,577^{*}$ & $-0,034^{\mathrm{ns}}$ & 0,089 \\
\hline \multicolumn{10}{|c|}{ 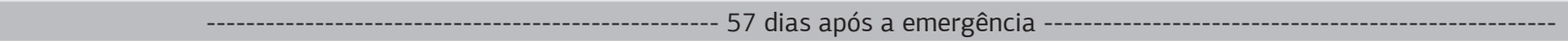 } \\
\hline CFC & 112 & 5,200 & 20,700 & 13,673 & 26,658 & 13,286 & $2,367^{\text {ns }}$ & $-0,281^{\mathrm{ns}}$ & 0,524 \\
\hline LFC & 112 & 3,800 & 15,200 & 9,779 & 29,013 & 8,049 & $2,220^{\text {ns }}$ & $-0,133^{\text {ns }}$ & 0,428 \\
\hline$C F C \times L F C$ & 112 & 21,280 & 307,040 & 143,814 & 50,734 & $5.323,453$ & $2,220^{\text {ns }}$ & $0,296^{\text {ns }}$ & 0,533 \\
\hline Y & 112 & 41,450 & 568,233 & 285,127 & 48,794 & $19.355,575$ & $2,061^{*}$ & $0,190^{\text {ns }}$ & 0,545 \\
\hline \multicolumn{10}{|c|}{ 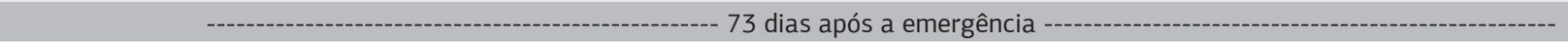 } \\
\hline CFC & 107 & 10,100 & 20,200 & 15,348 & 15,514 & 5,669 & $2,366^{\text {ns }}$ & $0,082^{\text {ns }}$ & 0,966 \\
\hline LFC & 107 & 6,600 & 15,800 & 11,141 & 17,584 & 3,838 & $2,377^{\text {ns }}$ & $0,100^{\text {ns }}$ & 0,670 \\
\hline $\mathrm{CFC} \times \mathrm{LFC}$ & 107 & 66,660 & 311,260 & 175,302 & 32,052 & $3.157,120$ & $2,513^{\text {ns }}$ & $0,400^{\text {ns }}$ & 0,743 \\
\hline Y & 107 & 142,155 & 624,040 & 338,801 & 33,460 & $12.851,002$ & $2,519^{\text {ns }}$ & $0,489^{*}$ & 0,273 \\
\hline \multicolumn{10}{|c|}{ 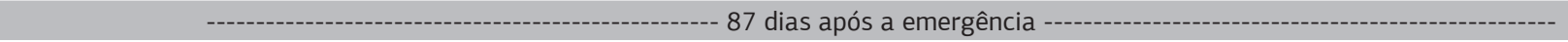 } \\
\hline CFC & 117 & 4,700 & 20,500 & 14,404 & 26,237 & 14,282 & $3,307^{\text {ns }}$ & $-0,988^{*}$ & 0,023 \\
\hline LFC & 117 & 2,900 & 16,200 & 10,313 & 29,579 & 9,305 & $3,052^{\text {ns }}$ & $-0,831^{*}$ & 0,004 \\
\hline$C F C \times L F C$ & 117 & 13,630 & 332,100 & 159,653 & 45,689 & $5.320,863$ & $2,556^{\mathrm{ns}}$ & $-0,312^{\text {ns }}$ & 0,350 \\
\hline Y & 117 & 27,310 & 670,908 & 317,345 & 45,902 & $21.219,036$ & $2,523^{\text {ns }}$ & $-0,333^{\text {ns }}$ & 0,131 \\
\hline \multicolumn{10}{|c|}{ 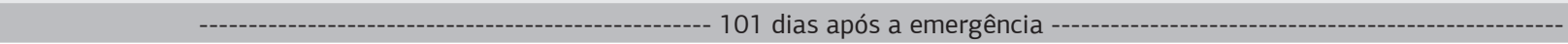 } \\
\hline CFC & 119 & 5,500 & 19,300 & 12,478 & 26,906 & 11,272 & $2,054^{*}$ & $-0,110^{\text {ns }}$ & 0,406 \\
\hline LFC & 119 & 3,800 & 15,100 & 8,504 & 31,890 & 7,355 & $2,203^{\text {ns }}$ & $0,174^{\text {ns }}$ & 0,511 \\
\hline $\mathrm{CFC} \times \mathrm{LFC}$ & 119 & 20,900 & 291,430 & 114,789 & 54,442 & $3.905,470$ & $2,537^{\mathrm{ns}}$ & $0,502^{*}$ & 0,302 \\
\hline Y & 119 & 42,181 & 640,535 & 237,886 & 54,365 & $16.725,632$ & $2,959^{\text {ns }}$ & $0,617^{*}$ & 0,488 \\
\hline \multicolumn{10}{|c|}{ } \\
\hline CFC & 605 & 4,700 & 22,300 & 14,075 & 26,972 & 14,412 & $2,438^{*}$ & $-0,401^{*}$ & 0,021 \\
\hline LFC & 605 & 2,900 & 16,200 & 9,960 & 29,869 & 8,850 & $2,295^{*}$ & $-0,325^{*}$ & 0,008 \\
\hline$C F C \times L F C$ & 605 & 13,630 & 354,570 & 151,162 & 50,218 & $5.762,349$ & $2,258^{*}$ & $0,156^{\text {ns }}$ & 0,172 \\
\hline Y & 605 & 22,203 & 686,299 & 296,249 & 50,051 & $21.985,494$ & $2,224^{*}$ & $0,129^{\text {ns }}$ & 0,306 \\
\hline
\end{tabular}

$\left({ }^{1}\right) *$ Curtose difere de três, pelo teste t, em nível de $5 \%$ de probabilidade. ${ }^{\text {ns: }}$ Não-significativo.

$\left({ }^{2}\right) *$ Assimetria difere de zero, pelo teste t, em nível de $5 \%$ de probabilidade. ${ }^{\text {ns: }}$ Não-significativo. 
fotos digitais, $\overline{\mathrm{Y}}$ é a média dos valores observados e n é o número de folhas $(\mathrm{n}=140)$. Após, obteve-se o índice CS de Camargo e Sentelhas (1997) pelo produto entre $\mathrm{r}$ e $\mathrm{d}(\mathrm{CS}=\mathrm{r} \times \mathrm{d})$.

Os critérios utilizados para a seleçấo dos modelos que melhor estimam a área foliar de feijão de porco em função do CFC, ou da LFC e/ou do CFC $\times$ LFC do limbo do folíolo central foram: coeficiente linear não diferente de zero, coeficiente angular não diferente de um, coeficientes de correlaçấo linear de Pearson e de determinação mais próximos de um, erro absoluto médio e raiz do quadrado médio do erro mais próximo de zero, eíndices $\mathrm{d}$ de Willmott (Willmott, 1981) e CS de Camargo e Sentelhas (1997) mais próximos de um. As análises estatísticas foram realizadas com auxílio do aplicativo Office Excel e do software Statistica 7.0 (STATSOFT, 2005).

$\mathrm{Na}$ cultura de feijão de porco (Canavalia ensiformis), com base em 605 folhas coletadas em seis períodos de desenvolvimento, houve padrôes lineares e não-lineares nas relaçôes do comprimento (CFC), da largura (LFC) e do produto do comprimento vezes a largura $(\mathrm{CFC} \times \mathrm{LFC})$ do limbo do folíolo central com a área foliar obtida por fotos digitais (Y) (Figura 1). Estes diferentes padrōes sugerem a necessidade de construir e testar diferentes modelos para a estimação da área foliar.

As dimensôes foliares médias das 605 folhas mensuradas foram, respectivamente, 14,075 e $9,960 \mathrm{~cm}$ de comprimento e de largura do limbo do folíolo central (Tabela 1). A área foliar média (soma da área foliar dos folíolos esquerdo, central e direito) foi de $296,249 \mathrm{~cm}^{2}$. Em média, os coeficientes de variação do comprimento (CFC) e da largura (LFC) do limbo do folíolo central foram semelhantes ( $C V=26,972 \%$ e $C V=29,869 \%$ respectivamente), e do produto do comprimento vezes largura (CFC $\times$ LFC) e da área foliar (Y) também tiveram semelhança entre si, no entanto, com valores de CV próximos a 50\%. Com base nessa ampla variabilidade das folhas coletadas, pode-se inferir que os dados são adequados para a construção de modelos de estimação da área foliar em função de dimensôes lineares, por contemplar folhas de diferentes tamanhos e em diferentes períodos de desenvolvimento da cultura.

Entre os seis períodos de desenvolvimento em que foram coletadas as folhas, nos dados de CFC, de LFC, de CFCxLFC e de Y, em apenas 29,17 e 20,83\% dos casos, respectivamente, verificou-se curtose diferente de

Tabela 2. Modelos para a determinação da área foliar, em $\mathrm{cm}^{2}(\mathrm{Y})$ por fotos digitais, utilizando o comprimento, em $\mathrm{cm}(\mathrm{CFC})$, a largura, em $\mathrm{cm}(\mathrm{LFC})$ e o produto comprimento vezes largura $(\mathrm{CFC} \times \mathrm{LFC})$ do limbo do folíolo central como variáveis independentes $(\mathrm{x})$ e coeficiente de determinação, com base em 605 folhas de feijão de porco (Canavalia ensiformis)

\begin{tabular}{lccc} 
Modelo & Variável independente $(\mathbf{x})$ & Equação & Coeficiente de determinação \\
1) Quadrático & CFC & $\hat{Y}=-32,7339+4,6241 x+1,2419 x^{2}$ & 0,9502 \\
\hline 2) Quadrático & LFC & $\hat{Y}=-28,7622+11,1487 x+1,9807 x^{2}$ & 0,9710 \\
3) Quadrático & CFC LFC & $\hat{Y}=-3,9600+2,0701 x-0,0004 x^{2}$ & 0,9771 \\
\hline 4) Potência & CFC & $\hat{Y}=1,0837 x^{2,0904}$ & 0,9704 \\
5) Potência & LFC & $\hat{Y}=3,7046 x^{1,8747}$ & 0,9757 \\
6) Potência & CFC $\times$ LFC & $\hat{Y}=1,9733 x^{0,9984}$ & 0,9831 \\
7) Linear & CFC & $\hat{Y}=-234,3917+37,7009 x$ & 0,9317 \\
8) Linear & LFC & $\hat{Y}=-188,7304+48,6944 x$ & 0,9545 \\
9) Linear & CFC $\times$ LFC & $\hat{Y}=4,4325+1,9305 x$ & 0,9768
\end{tabular}

Tabela 3. Variáveis independentes (x), coeficientes linear (a), angular (b), de correlação linear de Pearson (r) e de determinação ( $\left.\mathrm{R}^{2}\right)$, obtidos na regressão linear ajustada entre a área foliar estimada (variável dependente) e a observada (variável independente). Erro absoluto médio (EAM), raiz do quadrado médio do erro (RQME), índice d de Willmott (Willmott, 1981) e CS de Camargo e Sentelhas (1997) calculados com base nas áreas foliares estimada e observada, de 140 folhas de feijão de porco (Canavalia ensiformis)

\begin{tabular}{|c|c|c|c|c|c|c|c|c|c|}
\hline Modelo & $\mathbf{x}$ & $a^{(1)}$ & $\mathbf{b}^{(2)}$ & $r^{(3)}$ & $\mathbf{R}^{2}$ & EAM & RQME & d & CS \\
\hline 1) Quadrático & CFC & $15,653^{*}$ & $0,943^{*}$ & $0,975^{*}$ & 0,951 & 25,293 & 33,257 & 0,987 & 0,963 \\
\hline 2) Quadrático & LFC & $10,401^{*}$ & $0,984^{\mathrm{ns}}$ & $0,983^{*}$ & 0,968 & 21,224 & 27,696 & 0,991 & 0,975 \\
\hline 4) Potência & CFC & $8,818^{\text {ns }}$ & $0,963^{\text {ns }}$ & $0,974^{*}$ & 0,950 & 24,833 & 33,590 & 0,987 & 0,962 \\
\hline 5) Potência & LFC & $4,807^{\text {ns }}$ & $1,002^{\mathrm{ns}}$ & $0,983^{*}$ & 0,968 & 21,416 & 27,976 & 0,991 & 0,975 \\
\hline 6) Potência & $\mathrm{CFC} \times \mathrm{LFC}$ & $4,232^{\text {ns }}$ & $0,993^{\mathrm{ns}}$ & $0,989^{*}$ & 0,978 & 17,020 & 22,352 & 0,994 & 0,984 \\
\hline 7) Linear & CFC & $21,585^{*}$ & $0,922^{*}$ & $0,959 *$ & 0,921 & 32,719 & 42,048 & 0,979 & 0,940 \\
\hline 8) Linear & LFC & $17,173^{*}$ & $0,957^{*}$ & $0,969^{*}$ & 0,940 & 28,770 & 36,873 & 0,984 & 0,955 \\
\hline 9) Linear & $\mathrm{CFC} \times \mathrm{LFC}$ & $8,229^{\text {ns }}$ & $0,981^{\mathrm{ns}}$ & $0,989 *$ & 0,978 & 16,903 & 22,262 & 0,994 & 0,984 \\
\hline
\end{tabular}

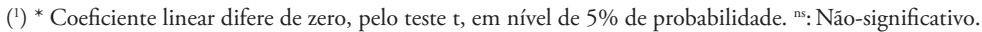

$\left({ }^{2}{ }^{*}\right.$ Coeficiente angular difere de um, pelo teste $t$, em nível de $5 \%$ de probabilidade. ns: Não-significativo.

$\left({ }^{3}\right) *$ Coeficiente de correlaçáo difere de zero, pelo teste t, em nível de $5 \%$ de probabilidade. 
três e assimetria diferente de zero, pelo teste t $(\mathrm{p} \leq 0,05)$ (Tabela 1). Ainda, somente para a LFC aos 43 DAE e para CFC e LFC aos $87 \mathrm{DAE}$, os dados náo apresentaram distribuição normal pelo teste de normalidade de Kolmogorov-Smirnov $(\mathrm{p} \leq 0,05)$. Esses resultados sugerem boa aderência dos dados à distribuição normal. Por outro lado, considerando as coletas analisadas em conjunto (605 folhas), a curtose foi menor que três, e apenas em CFC $\times$ LFC e Y houve assimetria não diferente de zero $(p>0,05)$ e distribuição normal $(p>0,05)$. Nesse caso, o elevado número de folhas (605) contribuiu para que pequenos desvios das estimativas em relação à hipótese de nulidade da curtose, da assimetria e da normalidade fossem significativos. Segundo Bussab e Morettin (2004), com base no teorema do limite central, mesmo que a população básica seja não normal, quando o número de observaçôes for superior a 30 , a distribuição da média amostral será aproximadamente normal. Assim, pode-se inferir que os dados, de maneira geral, ajustam-se à normalidade $\mathrm{e}$, consequentemente, oferecem credibilidade para a construção de modelos de estimação de área foliar.

Em todos os modelos construídos da área foliar obtida por fotos digitais em função do CFC, da LFC e do $\mathrm{CFC} \times \mathrm{LFC}$, os valores de coeficiente de determinação $\left(R^{2} \geq 0,9317\right)$ foram elevados (Tabela 2$)$, sugerindo a utilizaçáo de qualquer modelo para estimar a área foliar de feijão de porco. Porém, quanto ao tipo de modelo utilizado, no modelo tipo potência houve os melhores ajustes $\left(R^{2} \geq 0,9704\right)$, seguido do modelo quadrático $\left(R^{2} \geq 0,9502\right)$, concordando com Toebe et al. (2010) que também verificaram melhores ajustes destes modelos em relação ao modelo linear. Em relação às dimensôes foliares, melhores modelos foram obtidos quando se considera o produto do comprimento vezes largura (CFC $\times$ LFC) do limbo do folíolo central na estimação da área foliar $\left(R^{2} \geq 0,9768\right)$, concordando com Bianco et al. (2008) e Pinto et al. (2008), que em Sida cordifolia e Sida rhombifolia e em Curcuma alismatifolia e Curcuma zedoaria respectivamente, obtiveram modelos mais precisos a partir do produto do comprimento vezes a largura do limbo das folhas. Nos modelos construídos a partir da LFC $\left(R^{2} \geq 0,9545\right)$ os ajustes foram superiores aos obtidos a partir do CFC $\left(R^{2} \geq 0,9317\right)$. Em crambe, Toebe et al. (2010) também verificaram melhores ajustes dos modelos obtidos a partir da largura em relação ao comprimento.

Com base nos indicadores usados para a validação dos modelos, a partir de 140 folhas, verificou-se maior precisão dos modelos tipo potência $\left(\hat{\mathrm{Y}}=1,9733 \mathrm{x}^{0,9984}, \mathrm{R}^{2}=0,9831\right) \mathrm{e}$ linear $\left(\hat{Y}=4,4325+1,9305 x, R^{2}=0,9768\right)$; nesses modelos utiliza-se o CFC $\times$ LFC na estimação da área foliar, com coeficiente linear não diferente de zero, coeficiente angular não diferente de um, coeficientes de correlaçáo linear de Pearson e de determinação mais próximos de um, menor erro absoluto médio e raiz do quadrado médio do erro e, índices d de Willmott (Willmott, 1981) e CS de Camargo e Sentelhas (1997) mais próximos de um (Tabela 3). No entanto, a utilizaçáo alternativa do modelo tipo potência em função da LFC $\left(\hat{Y}=3,7046 x^{1,8747}\right.$, $\left.\mathrm{R}^{2}=0,9757\right)$ é recomendada, pois este modelo atende aos critérios de validação estabelecidos neste trabalho de modo semelhante aos modelos com base no CFC $\times$ LFC, necessitando apenas da mensuração da largura do limbo do folíolo central.

\section{REFERÊNCIAS}

ADAMI, M.; HASTENREITER, F.A.; FLUMIGNAN, D.L.; FARIA, R.T. Estimativa de área de folíolos de soja usando imagens digitais e dimensões foliares. Bragantia, v.67, p.1053-1058, 2008.

ALMEIDA, E.L.; MARCOS, F.C.C.; SCHIAVINATO, M.A.; LAGÔA, A.M.M.A.; ABREU, M.F. Crescimento de feijāo-deporco na presença de chumbo. Bragantia, v.67, p.569-576, 2008.

BIANCO, S.; CARVALHO, L.B.; BIANCO, M.S. Estimativa da área foliar de Sida cordifolia e Sida rhombifolia usando dimensóes lineares do limbo foliar. Planta Daninha, v.26, p.807-813, 2008.

BUSSAB, W.O.; MORETTIN, P.A. Estatística básica. 5.ed. São Paulo: Saraiva, 2004. 526p.

CAMARGO, A.P.; SENTELHAS, P.C. Avaliação do desempenho de diferentes métodos de estimativa da evapotranspiração potencial no estado de São Paulo, Brasil. Revista Brasileira de Agrometeorologia, v.5, p.89-97, 1997.

JANDEL SCIENTIFIC. User's Manual. California, 1991. 280p.

PINTO, A.C.R.; GRAZIANO, T.T.; BARBOSA, J.C.; LASMAR, F.B. Modelos para estimativa da área foliar de Curcuma alismatifolia e Curcuma zedoaria. Bragantia, v.67, p.549-552, 2008.

SOUZA FILHO, A.P.S. Atividade potencialmente alelopática de extratos brutos e hidroalcoólicos de feijão-de-porco (Canavalia ensiformis). Planta Daninha, v.20, p.357-364, 2002.

STATSOFT. Statistica 7.0 Software. Tucksa, USA, 2005.

TAVARES JUNIOR, J.E.; FAVARIN, J.L.; DOURADO NETO, D.; MAIA, A.; H.N.; FAZUOLI, L.C.; BERNARDES, M.S. Análise comparativa de métodos de estimativa de área foliar em cafeeiro. Bragantia, v.61, p.199-203, 2002.

TEIXEIRA, C.M.; CARVALHO, G.J.; SILVA, C.A.; ANDRADE, M.J.B.; PEREIRA, J.M. Liberaçáo de macronutrientes das palhadas de milheto solteiro e consorciado com feijão-de-porco sob cultivo de feijão. Revista Brasileira de Ciência do Solo, v.34, p.497-506, 2010 .

TOEBE, M.; BRUM, B.; LOPES, S.J.; CARGNELUTTI FILHO, A.; SILVEIRA, T.R. Estimativa da área foliar de Crambe abyssinica por discos foliares e por fotos digitais. Ciência Rural, v.40, p.445448, 2010.

WILLMOTT, C.J. On the validation of models. Physical Geography, v.2, p.184-194, 1981. 